Additional services for Psychological Medicine:

Email alerts: $\underline{\text { Click here }}$

Subscriptions: Click here

Commercial reprints: Click here

Terms of use : $\underline{\text { Click here }}$

\title{
Worry content across the lifespan: an analysis of 16- to 74- year-old participants in the British National Survey of Psychiatric Morbidity 2000
}

\author{
JAMES LINDESAY, SARAH BAILLON, TRAOLACH BRUGHA, MICHAEL DENNIS, ROBERT \\ STEWART, RICARDO ARAYA and HOWARD MELTZER
}

Psychological Medicine / Volume 36 / Issue 11 / November 2006, pp 1625 - 1633

DOI: 10.1017/S0033291706008439, Published online: 25 July 2006

Link to this article: http://journals.cambridge.org/abstract_S0033291706008439

How to cite this article:

JAMES LINDESAY, SARAH BAILLON, TRAOLACH BRUGHA, MICHAEL DENNIS, ROBERT STEWART, RICARDO ARAYA and HOWARD MELTZER (2006). Worry content across the lifespan: an analysis of 16- to 74-year-old participants in the British National Survey of Psychiatric Morbidity 2000. Psychological Medicine, 36, pp 1625-1633 doi:10.1017/S0033291706008439

Request Permissions : $\underline{\text { Click here }}$ 


\title{
Worry content across the lifespan: an analysis of 16- to 74-year-old participants in the British National Survey of Psychiatric Morbidity 2000
}

\author{
JAMES LINDESAY ${ }^{1 *}$, SARAH BAILLON ${ }^{1}$, TRAOLACH BRUGHA ${ }^{1}$, MICHAEL \\ DENNIS ${ }^{1}$, ROBERT STEWART ${ }^{2}$, RICARDO ARAYA ${ }^{3}$ AND HOWARD MELTZER ${ }^{1}$ \\ ${ }^{1}$ Department of Health Sciences, University of Leicester, Leicester General Hospital, Leicester, UK; \\ ${ }^{2}$ King's College London (Institute of Psychiatry), Section of Epidemiology, London, UK; ${ }^{3}$ Division of \\ Psychiatry, University of Bristol, Bristol, UK
}

\begin{abstract}
Background. Previous studies suggest that worry content and prevalence may vary as a function of age, but evidence is limited.

Method. Cross-sectional national survey of 8580 householders in Great Britain aged between 16 and 74 years. This analysis examined the relationship between age, worry content (relationships/ family, financial/housing, work, health, miscellaneous), common mental disorders, and functional limitation, adjusting for other sociodemographic factors.

Results. Overall, the prevalence of worries declined with age. However, with the exception of worry about relationships, the strength of associations between worry types and mental disorder either remained constant or increased in the older age groups. Compared to the 16-24 years reference group, worries about relationships/family, finances/housing and work were lower in the 55-74 years age groups. Financial/housing worries were increased in the 25-44 years group, and health worries were increased in the 25-64 years groups. There were independent associations between all worry items and the categories of mental disorder. All worry types apart from miscellaneous worries were independently associated, positively or negatively, with functional limitation.
\end{abstract}

Conclusions. Worry content in the general population varies as a function of age, gender, marital status, and educational attainment. All categories of worry are more prevalent in individuals with common mental disorders. The lower prevalence of worries and their stronger association with mental disorder in old age emphasize the clinical significance of these symptoms in this age group.

\section{INTRODUCTION}

Worry is common in the general population at all ages, and occurs in all of the common mental disorders, such as depression and generalized anxiety (Singleton et al. 2001). Pathological worry is defined in terms of frequency, intensity and controllability, and worry content is not currently thought to have diagnostic significance (WHO, 1993; APA, 1994). There is, however, some evidence for qualitative as well as

\footnotetext{
* Address for correspondence: Professor J. Lindesay, Psychiatry for the Elderly, Leicester General Hospital, Leicester LE5 4PW, UK. (Email: jebl1@1e.ac.uk)
}

quantitative differences in the worries of those who do and do not meet diagnostic criteria for mental disorders. Clinical studies in younger adults have suggested that patients with generalized anxiety disorder (GAD) are more likely to worry about minor matters than are controls (Craske et al. 1989; Roemer et al. 1997; Hoyer et al. 2001) or those with other disorders, such as social phobia (Hoyer et al. 2001). In community samples, this has also been reported in the elderly (Montorio et al. 2003), but not in young females (Becker et al. 2003). One study comparing volunteer samples of older individuals with and without GAD found no differences 
in worry content between the older groups (Diefenbach et al. 2001a); however, they did find differences between their older groups and the younger groups reported by Roemer et al. (1997), with older individuals worrying more about health and less about work. Several studies have also found that, contrary to some stereotypes, older adults report significantly fewer worries overall than younger age groups (e.g. Powers et al. 1992; Doucet et al. 1998; Skarborn \& Nicki, 2000; Hunt et al. 2003). This suggests that both the content and frequency of worry may vary as a function of age, which has implications for the assessment, diagnosis and treatment of disorders such as GAD in older individuals, in whom these conditions are often unrecognized and poorly treated (Diefenbach et al. 2001a). As Hunt et al. (2003) point out, if different age groups have different concerns and methods of coping, then diagnostic assessments and cognitive-behavioural and problem-solving interventions may need to be adapted to address these issues, and to take account of any agespecific strengths and weaknesses.

Research into worry content is also important in helping us to understand better the nature and function of worry (Diefenbach et al. 2001 b). Most cognitive formulations focus on its pathological aspects, regarding it as the cognitive driver of anxious affect (Beck \& Emery, 1985), or as an avoidance activity in which worry about minor issues keeps more painful thoughts at bay (Borovec \& Roemer, 1995). More positively, it has been proposed that worry may be a problem-oriented coping mechanism that acts to reduce anxiety (Davey, 1994); if so, studies of worry in those with and without mental disorder may help to identify those factors associated with pathological as opposed to nonpathological worry.

Methodological limitations of studies into worry content to date limit the conclusions that can be drawn. Some are confined to clinical populations or to specific age and gender groups; numbers are often small; comparisons are made between specific age groups rather than by examining the interaction between mental disorder and worry across the age span; and few studies have controlled for the confounding effects of other sociodemographic variables, such as gender, marital status and educational attainment. The principal aim of this study was to study the relationship between age, worry content and mental disorder, adjusting for a range of sociodemographic factors in a large, representative community sample. Specifically, we aimed to examine the following hypotheses: that the specific content of worry changes with age; that the likelihood of worry declines rather than increases with increasing age after controlling for the effects of other sociodemographic variables; and that this agerelated decline also occurs in those with mental disorder.

\section{METHOD}

\section{Study sample}

Data were analysed from the second National Survey of Psychiatric Morbidity, carried out in Great Britain (England, Wales and Scotland) in 2000 by the Office for National Statistics (Singleton et al. 2001). Small area postcode units (postcode sectors) were selected randomly from a sampling frame stratified for region and social class composition to generate a nationally representative sample. Households were selected randomly from within each unit and, in each household containing at least one person aged between 16 and 74 years, one person was selected randomly and invited to participate. A total of 12792 adults were approached, with 8580 participants.

\section{Measures}

\section{Worry content}

Information on worry content was collected as part of the revised Clinical Interview Schedule (CIS-R) (Lewis et al. 1992), which was administered to all participants. Those who admitted to worrying or feeling depressed (within the past month) were shown a card with a list of 11 worry items (Table 1), and asked which had been making them worry. They were then asked to identify from the selected items the single main cause of their worry. Subjects who when asked were unable to identify specific worry topics were excluded. For this analysis, the worry items were grouped into the five content areas usually employed in studies of this topic (Craske et al. 1989; Sanderson \& Barlow, 1990; Diefenbach et al. 2001a): relationships/ family, financial/housing, work, health, and miscellaneous. 
Table 1. Worry items

\begin{tabular}{l}
\hline \hline Relationships/family \\
Relationship with partner \\
Relationship with friends \\
Members of family \\
Financial/housing \\
Money/bills \\
Housing \\
Work \\
Work or lack of work \\
Health \\
Own physical health \\
Own mental health \\
Miscellaneous \\
Legal difficulties \\
Political issues/the news \\
Other \\
\hline \hline
\end{tabular}

\section{Sociodemographic factors}

The following were included, on the basis that they have been shown to have univariate associations with worry in previous studies (e.g. Hunt et al. 2003):

(1) Gender.

(2) Age, categorized into 10-year bands (9-year band for the youngest group).

(3) Educational attainment, categorized in terms of highest qualification: no qualification; GCSE or equivalent (GCSE examinations usually taken at age 16 years); A-level or higher (A-level examinations usually taken at 18 years).

(4) Marital status: married/cohabiting, separated, single, divorced, widowed.

\section{Explanatory variables}

For certain worry types, the impact of specific possible explanatory variables in the survey data set were examined by entering them into the logistic regression models, as follows:

(1) Financial/housing worries: presence/absence of debt (seriously behind with payment of one or more household bills in the previous year).

(2) Work worries: employment status [working full-time, working part-time, unemployed, economically inactive (student, ill/disabled, retired)].

(3) Health worries: presence/absence of any self-reported longstanding physical illness.

\section{Mental disorder}

The CIS-R is a widely used fully structured assessment of psychiatric morbidity (Jordanova et al. 2004). Common mental disorder (CMD) was defined from this instrument using standard criteria (Lewis et al. 1992): scores from each of the 14 sections of the CIS-R are totalled to give an overall score (maximum 57 points), and CMD is defined as present on the basis of a score of 12 or above. In addition, ICD-10 diagnoses of GAD and depression were also derived from the survey data using standard algorithms.

\section{Life events}

As worry and worry content may be influenced by recent exposure to significant adverse life events (Hunt et al. 2003), this factor was also adjusted for. During the interview, subjects were shown cards listing a range of 12 adverse life events, derived from the List of Threatening Experiences questionnaire (Brugha et al. 1985), and asked to identify those that they had experienced within the previous 6 months. Examples of life events include: serious illness, injury or an assault to self or close relative; death of parent, child or spouse; separation due to marital difficulties.

\section{Functional limitation}

Information was collected about limitations in seven domains of activities of daily living (ADL): personal care, use of transport, medical care, household activities, practical activities, paperwork, and managing money (Meltzer et al. 2002). Subjects were classified as impaired on ADL if they responded positively to one or more of these items.

\section{Statistical analysis}

Data were analysed using STATA software, version 8 (StataCorp, College Station, TX, USA). All analyses were carried out using standard weighting procedures to allow for the stratified, clustered sampling and non-response. The associations between worry item groups and dependent sociodemographic and mental disorder variables were analysed using logistic regression. Effect modification was tested by entering an interaction term between worry item group and age (six groups) for given dependent variables, to examine its independent 
significance in the model. All models included gender, education, marital status and recent exposure to adverse life events as potential confounding factors; analyses of functional limitation also adjusted for mental and physical ill-health (CMD, self-reported longstanding physical illness).

\section{RESULTS}

The weighted mean age of the sample was 42.6 years (standard error $0 \cdot 22$ ), and $50 \cdot 1 \%$ were female. GAD was present in $431(4.4 \%)$, depression in $255(2.6 \%)$, and any CMD in 1400 $(15 \%)$. A total of $5439(63.4 \%)$ of the sample reported feelings of depression or worry in the previous month, with data on worry content available for $5294(97 \cdot 3 \%)$. About one quarter of the sample $(2242,26 \cdot 1 \%)$ reported experiencing one or more significant adverse life events in the previous 6 months.

\section{Age}

As Table 2 shows, the five worry item groups differed in their independent associations with demographic variables in this sample. Fig. 1 shows the different profiles of relationships between worry types and age. Overall, the prevalence of worries reduces with age. Compared to the 16-24 years reference group, worries about relationships/family, finances/housing and work were significantly lower in the 55-74 years age groups. Financial/housing worries were increased in the 25-44 years group, and health worries were increased in those over 24 , although this was only significant for the 25-64 years groups.

\section{Other sociodemographic variables}

Female gender was associated with worries about relationships/family [odds ratio (OR) $2 \cdot 00,95 \%$ confidence interval (CI) $1 \cdot 78-2 \cdot 19$, $t=12 \cdot 63, p<0 \cdot 0001]$ and health (OR 1.23, 95\% CI $1.07-1.41, t=3.02, p=0.003)$, and male gender with worries about work (OR 1·62, $95 \%$ CI $1.44-1 \cdot 83, t=7 \cdot 85, p<0 \cdot 0001)$. There were significant age variations in the association between gender and worry about work (OR $1 \cdot 13$, $95 \%$ CI $1.03-1 \cdot 24, t=2 \cdot 58, p=0.01)$, worry about finances/housing (OR $1 \cdot 10,95 \%$ CI $1 \cdot 02-1 \cdot 18, t=2 \cdot 46, p=0 \cdot 014)$ and worry about health (OR $1 \cdot 16,95 \%$ CI $1 \cdot 06-1 \cdot 27, t=3 \cdot 31$, $p=0.001$ ), with males reporting more worry with increasing age, and females reporting less. Worry about relationships/family was greater in the separated and divorced, worry about health was increased in the separated and divorced, and financial/housing and miscellaneous worries were increased in all groups compared to the married (Table 2).

\section{Explanatory variables}

When presence/absence of debt was included in the logistic regression model for financial/ housing worries, this did not significantly alter the independent associations of this worry type with age, gender or marital status. Debt was associated with financial worries (OR 4.07, $95 \%$ CI $3 \cdot 43-4 \cdot 83, t=16 \cdot 08, p<0 \cdot 0001)$.

There were no significant changes in the independent associations between worry about work and age, gender, marital status or education when employment status was entered into the model for this worry type. Part-time employment, unemployment and being economically inactive were all associated with more worries about work than full-time employment.

The presence of a longstanding physical complaint was significantly associated with worry about health (OR $2 \cdot 9,95 \%$ CI $2 \cdot 51-3 \cdot 36$, $t=14.39, p<0.0001)$. When this variable was included in the logistic regression model for health worries, this worry type emerged as significantly less common in the 65-74 years group than in the reference group (OR $0 \cdot 70,95 \% \mathrm{CI}$ $0 \cdot 49-1 \cdot 00, t=1 \cdot 99, p<0 \cdot 05)$.

\section{Mental disorder}

There were strong independent associations for all worry item groups with CMD, GAD and depression (Table 3). These three categories of mental disorder were also associated with a greater number of worry items in all age and sex groups (data not shown). There was a significant correlation between the number of worry items and CIS-R score $\left(R^{2}=0.33, p<0.0001\right)$. Exposure to one or more adverse life events in the previous 6 months was also associated with all worry item groups (Table 3 ).

With regard to the associations between worry item groups and CMD, there were significant linear age interactions as follows: the association increased with age for worry about work (OR $1 \cdot 16,95 \%$ CI $1 \cdot 04-1 \cdot 29, t=2 \cdot 77$, 
Table 2. Associations between demographic measures and worry items

\begin{tabular}{|c|c|c|c|c|c|c|c|c|c|c|c|}
\hline & \multirow[b]{2}{*}{$n$} & \multicolumn{2}{|c|}{ Relationships } & \multicolumn{2}{|r|}{ Finances } & \multicolumn{2}{|r|}{ Work } & \multicolumn{2}{|r|}{ Health } & \multicolumn{2}{|c|}{ Miscellaneous } \\
\hline & & $\%$ & OR $(95 \% \mathrm{CI})$ & $\%$ & OR $(95 \% \mathrm{CI})$ & $\%$ & OR $(95 \% \mathrm{CI})$ & $\%$ & OR $(95 \% \mathrm{CI})$ & $\%$ & OR $(95 \% \mathrm{CI})$ \\
\hline \multicolumn{12}{|l|}{ Age (years) } \\
\hline $16-24$ & 794 & $38 \cdot 3$ & $1 \cdot 00$ & $31 \cdot 8$ & $1 \cdot 00$ & $33 \cdot 4$ & $1 \cdot 00$ & $11 \cdot 5$ & $1 \cdot 00$ & $20 \cdot 3$ & $1 \cdot 00$ \\
\hline $25-34$ & 1683 & $35 \cdot 5$ & $0.85(0.69-1.06)$ & 38.9 & $1.52(1.23-1.88)^{* *}$ & 33.9 & $1.03(0.83-1.29)$ & $14 \cdot 8$ & $1.43(1.06-1.91)^{*}$ & $15 \cdot 9$ & $0.80(0.61-1 \cdot 05)$ \\
\hline $35-44$ & 1848 & $39 \cdot 1$ & $0 \cdot 95(0 \cdot 76-1 \cdot 20)$ & $34 \cdot 6$ & $1 \cdot 26(1.00-1 \cdot 58)^{*}$ & $31 \cdot 5$ & $1.03(0.82-1.29)$ & $16 \cdot 1$ & $1.57(1 \cdot 18-2 \cdot 08)^{* *}$ & $13 \cdot 0$ & $0.67(0.51-0.89)^{* *}$ \\
\hline $45-54$ & 1545 & 38.9 & $0.96(0.76-1.21)$ & $25 \cdot 5$ & $0.81(0.64-1.04)$ & $28 \cdot 5$ & $0.95(0.74-1.22)$ & $17 \cdot 4$ & $1.74(1.30-2.33)^{* *}$ & $13 \cdot 4$ & $0.74(0.55-1.00)^{*}$ \\
\hline $55-64$ & 1442 & $33 \cdot 2$ & $0.78(0.62-1.00)^{*}$ & $16 \cdot 5$ & $0.48(0.37-0.63)^{* *}$ & $13 \cdot 0$ & $0.41(0.31-0.54)^{* *}$ & $14 \cdot 2$ & $1.40(1.03-1.91)^{*}$ & $12 \cdot 7$ & $0.73(0.54-0.99)^{*}$ \\
\hline $65-74$ & 1268 & $27 \cdot 3$ & $0.60(0.47-0.78)^{* *}$ & $11 \cdot 5$ & $0.31(0.23-0.41)^{* *}$ & $1 \cdot 5$ & $0.04(0.03-0.07)^{* *}$ & $11 \cdot 6$ & $1 \cdot 12(0 \cdot 80-1 \cdot 56)$ & $12 \cdot 1$ & $0.70(0.50-0.97)^{*}$ \\
\hline \multicolumn{12}{|l|}{ Sex } \\
\hline Male & 3852 & $28 \cdot 6$ & $1 \cdot 00$ & $27 \cdot 8$ & $1 \cdot 00$ & $30 \cdot 7$ & $1 \cdot 00$ & $13 \cdot 4$ & $1 \cdot 00$ & $14 \cdot 2$ & $1 \cdot 00$ \\
\hline Female & 4728 & $43 \cdot 5$ & $1.97(1.78-2 \cdot 19)^{* *}$ & $28 \cdot 6$ & $1 \cdot 06(0 \cdot 95-1 \cdot 18)$ & $20 \cdot 6$ & $0 \cdot 62(0 \cdot 55-0 \cdot 70)^{* *}$ & $15 \cdot 8$ & $1.23(1.07-1.41)^{* *}$ & $15 \cdot 1$ & $1.09(0.94-1 \cdot 26)$ \\
\hline \multicolumn{12}{|l|}{ Education } \\
\hline None & 2565 & $34 \cdot 1$ & $1 \cdot 00$ & $23 \cdot 3$ & $1 \cdot 00$ & $13 \cdot 7$ & $1 \cdot 00$ & $15 \cdot 1$ & $1 \cdot 00$ & 11.7 & $1 \cdot 00$ \\
\hline GCSE & 2968 & $36 \cdot 8$ & $1 \cdot 06(0 \cdot 92-1 \cdot 21)$ & $28 \cdot 8$ & $0 \cdot 96(0 \cdot 82-1 \cdot 12)$ & $23 \cdot 8$ & $1.33(1 \cdot 11-1 \cdot 60)^{* *}$ & $13 \cdot 6$ & $0.88(0.74-1.04)$ & $15 \cdot 0$ & $1.27(1.05-1.53)^{* *}$ \\
\hline A-level & 2982 & $36 \cdot 8$ & $1 \cdot 13(0 \cdot 98-1 \cdot 31)$ & $31 \cdot 6$ & $1.08(0.92-1.27)$ & $36 \cdot 7$ & $2 \cdot 36(1.96-2 \cdot 84)^{* *}$ & $15 \cdot 3$ & $1 \cdot 01(0 \cdot 84-1 \cdot 22)$ & $16 \cdot 6$ & $1.46(1.20-1.77)^{* *}$ \\
\hline \multicolumn{12}{|c|}{ Marital status } \\
\hline Married & 4383 & $34 \cdot 3$ & $1 \cdot 00$ & $23 \cdot 0$ & $1 \cdot 00$ & $23 \cdot 0$ & $1 \cdot 00$ & 13.9 & $1 \cdot 00$ & $12 \cdot 3$ & $1 \cdot 00$ \\
\hline Separated & 360 & $60 \cdot 8$ & $2.51(1.90-3.30)^{* *}$ & $48 \cdot 3$ & $2.49(1.88-3.30)^{* *}$ & $24 \cdot 9$ & $0.95(0 \cdot 70-1 \cdot 28)$ & $20 \cdot 1$ & $1.41(1.03-1.94)^{*}$ & $18 \cdot 7$ & $1.52(1.10-2.09)^{* * *}$ \\
\hline Single & 2279 & $35 \cdot 1$ & $0 \cdot 92(0 \cdot 80-1 \cdot 06)$ & $34 \cdot 2$ & $1.25(1.06-1.47)^{* *}$ & $34 \cdot 0$ & $1 \cdot 13(0 \cdot 96-1 \cdot 33)$ & $13 \cdot 7$ & $1 \cdot 14(0.94-1 \cdot 39)$ & $18 \cdot 1$ & $1.23(1.02-1.48)^{*}$ \\
\hline Divorced & 982 & $44 \cdot 7$ & $1.41(1 \cdot 20-1 \cdot 66)^{* *}$ & $38 \cdot 9$ & $2.03(1.71-2.41)^{* *}$ & $23 \cdot 3$ & $0.98(0 \cdot 80-1 \cdot 20)$ & $20 \cdot 9$ & $1.51(1.23-1.86)^{* *}$ & $15 \cdot 7$ & $1.31(1.05-1 \cdot 64)^{*}$ \\
\hline Widowed & 576 & $32 \cdot 3$ & $0.97(0 \cdot 79-1 \cdot 20)$ & $20 \cdot 6$ & $1 \cdot 70(1.26-2 \cdot 28)^{* *}$ & $5 \cdot 6$ & $0 \cdot 70(0.46-1.08)$ & $14 \cdot 3$ & $1 \cdot 11(0 \cdot 83-1 \cdot 48)$ & $16 \cdot 1$ & $1 \cdot 53(1 \cdot 17-2 \cdot 01)^{* * *}$ \\
\hline
\end{tabular}

OR, Odds ratio, adjusted for age, gender, education, marital status, and exposure to life events; CI, confidence interval.

OR, Odds ratio, adjusted
$* p<0 \cdot 05, * * \quad p<0 \cdot 01$ 


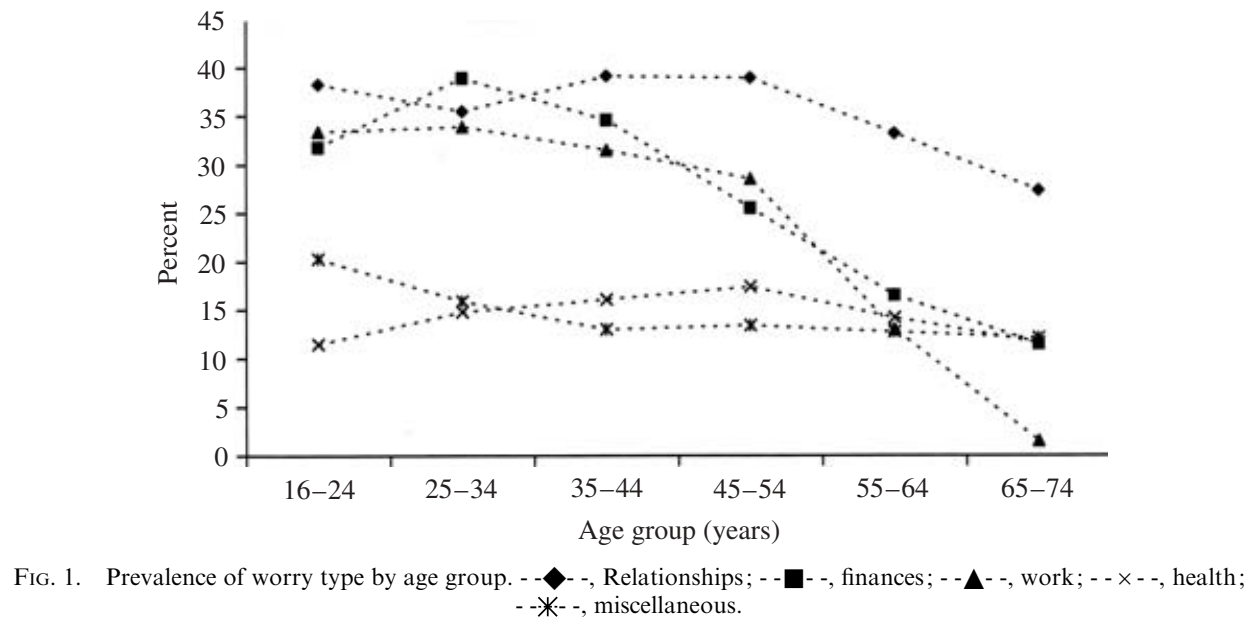

$p=0.006)$ and for miscellaneous worries (OR $1 \cdot 18,95 \%$ CI $1 \cdot 07-1 \cdot 30, t=3 \cdot 42, p=0 \cdot 001)$; it decreased with age for worry about relationships/family (OR 0.86 , 95\% CI $0.79-0.94$, $t=3 \cdot 38, p=0 \cdot 001)$. Similar patterns of association were found when GAD and depression were analysed as separate outcomes (data not shown). There were no significant age interactions across the age range for worries about finances/housing and health, but the former was most strongly associated with CMD in the youngest 16-24 years age group, and the latter most strongly associated with CMD in the oldest 65-74 years age group.

\section{Functional limitation}

All worry item groups apart from miscellaneous worries were independently associated with functional limitation (impaired on one or more ADL) (Table 3). These associations were positive in all cases except for worry about work, which was negatively associated with functional limitation. The strength of these associations decreased with increasing age for worry about relationships/family (OR $0 \cdot 88,95 \%$ CI $0 \cdot 80$ $0 \cdot 96, t=2 \cdot 87, p=0 \cdot 004)$, worry about finances/ housing (OR $0.91,95 \%$ CI $0 \cdot 82-1 \cdot 00, t=1 \cdot 99$, $p=0.047$ ) and worry about work (OR 0.87, $95 \%$ CI $0 \cdot 76-0 \cdot 99, t=2 \cdot 12, p=0 \cdot 035)$.

\section{DISCUSSION}

This study has a number of advantages over previous research into worry content: it is based on a large and nationally representative sample, the diagnoses of mental disorder have been developed using validated epidemiological methods, and important confounding factors such as sociodemographic variables and life events are adjusted for. There are also some limitations. The upper age cut-off of this sample is 74 years, so no conclusions can be drawn about worry in more elderly individuals. The survey items dealing with worry were necessarily brief, and no data are available on some aspects of worry, such as controllability, frequency, intensity, and coping style, that have been examined in smaller but more intensive studies using instruments such as the Penn State Worry Questionnaire (PSWQ; Meyer et al. 1990). Only those subjects who reported being worried or depressed in the previous month were asked about the content of their worries, so this survey will not have identified the milder concerns of those without worry or depressed mood over this time period. This survey was crosssectional, so it is not possible to attribute causality, or to distinguish between age, period and cohort effects.

\section{Worry and age}

The findings of this study support the hypothesis, based upon previous research, that after adjustment for confounding factors older adults report significantly fewer worries overall than younger age groups. This age-associated decline is probably due to a number of specific age, period and cohort effects beyond the scope of 


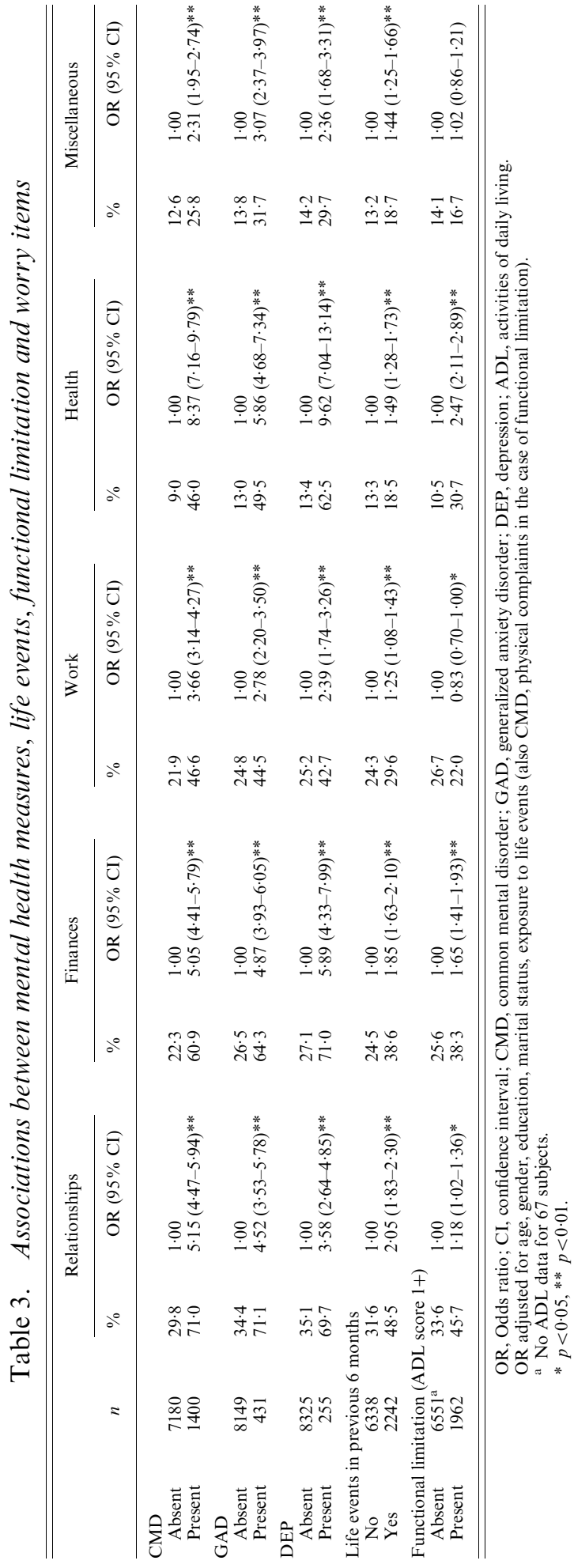

this study design to investigate. There is some evidence that younger and older adults have different coping styles: more active and problem-focused in the young, more passive and emotion-focused in the old (Folkman et al. 1987). Perhaps increasing age and life experience brings increased mental resilience and 'wise detachment' (Valliant, 1977); old age certainly brings retirement, which currently removes the need for many individuals to worry about work. Alternatively, there may be cohort effects, with different generations showing different levels of liability to worry in the face of adversity. Specific period effects, particularly those related to employment and income, may also have different effects at different ages. The current cohort of 65- to 74-year-olds is well provided for in retirement by occupational pensions and other sources of income; in this sample only $21 \%$ of this age group were reliant on state pensions and benefits alone. This trend may continue beyond the 74-year cut-off point of our study; Doucet et al. (1998) found that individuals aged 75 years and over worried less than those aged 55-64 years about the future, work and finances.

Worry about health is also a feature of young adulthood and middle age rather than old age (up to 74 years) in this sample. Indeed, if the presence or absence of a longstanding illness is adjusted for, the 65-74 years group had the lowest rate of health worries, although it should be borne in mind that self-reported illness may be a function of that worry. In addition to the age, period and cohort effects mentioned above, this age-associated decline in health worries may also be a survivor effect, in that younger adults with the most severe health problems (and presumably worries) die before they reach old age. Worry about health may be more prevalent in those aged over 75, as suggested by Hunt et al. (2003), whose older group contained individuals up to the age of 86 who worried more about this topic than their young 18-25 years group.

\section{The impact of other sociodemographic variables}

This study confirms the need to control for the effect of other sociodemographic variables that have their own independent association with worry. In this sample as a whole, women worried more about relationships/family and health, but less than men about work, although the gender difference was absent in levels of 
worry about work in the youngest and oldest age groups. A similar low level of worry about work in the post-retirement age group is to be expected; the lack of a gender difference in the youngest age group may be due to their equal involvement in the workplace in this age cohort. In this context, it is interesting that younger females were also more worried than males about finances/housing, a finding reported by Hunt et al. (2003). In the case of worry about finance, work and health, analysis of the age variations of their association with gender shows that the sex differences become less with increasing age.

This study also confirms the finding of Hunt et al. (2003) that the experience of worry varies with marital status. Unlike Hunt et al., however, the single and widowed groups did not differ in levels of worry in our sample, perhaps because our analysis controlled for the effect of age.

\section{Mental disorder and functional limitation}

Worry is clinically important. After controlling for sociodemographic variables and recent exposure to life events, strong independent associations remain between all worry item groups and the three categories of mental disorder examined in this study (CMD, GAD, depression). For each category of disorder, worries about health, finances/housing and relationships/family are the most prevalent concerns; in the case of health, it should be noted that this worry item included 'worry about one's mental health', which may have strengthened this association. In contrast to the age-associated decline in worry in the overall sample, the rates of all worry types associated with mental disorder either remain constant or increase in the oldest age groups, with the notable exception of worry about relationships/family. There was no significant age interaction in the association between worry about health and mental disorder in this sample, which runs counter to previous reports in relation to GAD (Montorio et al. 2003) and the usual perception that elderly people are particularly susceptible to this concern (Rodin \& Timko, 1992; Hunt et al. 2003). It is the case, however, that the strongest associations between CMD and worry about health were with the oldest age groups, and inclusion of subjects over the age of 74 years might have reinforced this trend.

The worry items were also independently associated with functional limitation in this sample, although less strongly than with mental disorder, and not always positively. It may be therefore that, in younger age groups at least, worries about family/relationships, finances/ housing and health are disabling in their own right, separate from any relationship with physical and mental disorder. Alternatively, there may be degrees or episodes of disabling physical and mental disorder or disability associated with worry in this sample that are not captured by the variables used here to adjust for them (CMD and self-reported longstanding physical complaints). The negative association between functional limitation and worry about work is anomalous. Further analysis (data not shown) indicates that this is significant only for more severe degrees of functional limitation, so this may reflect the fact that more severely disabled individuals are relieved of the need to seek or hold down a job, and therefore the worry associated with this.

The sustained or increased strength of association between most worry items and mental disorder with increasing age, while relatively modest, is in contrast to a decline in the rate of worries with increasing age in the sample as a whole (Table 2). This suggests that the pathological significance of worry may vary with age, with specific worries being more indicative of mental disorder in old age than in younger adulthood. The reasons for this are not clear. It could be that this cohort of older adults are more efficient worriers whose concerns resolve more quickly if they do not develop into an episode of mental disorder. Another possibility is that this group uses fewer or less effective coping mechanisms to manage their worries, so increasing the risk of conversion to disorder (Hunt et al. 2003). Further research on the process, duration and outcome of worry at different ages is needed to resolve this point.

\section{CONCLUSIONS}

The findings of this study indicate that worry content in the general population varies as a function of age, gender, marital status and 
educational attainment. All categories of worry are more prevalent in individuals with common mental disorders. The lower prevalence of worries and a stronger association with mental disorder in old age is a reminder that significant worry in this age group should not be dismissed, but should prompt further assessment of the mental state.

\section{DECLARATION OF INTEREST}

None.

\section{REFERENCES}

APA (1994). Diagnostic and Statistical Manual of Mental Disorders (4th edn). American Psychiatric Association: Washington, DC.

Beck, A. T. \& Emery, G. (1985). Anxiety Disorders and Phobias: A Cognitive Perspective. Basic Books: New York.

Becker, E., Goodwin, R., Hölting, C., Hoyer, J. \& Margraf, J. (2003). Content of worry in the community: what do people with generalized anxiety disorder or other disorders worry about? Journal of Nervous and Mental Disease 191, 688-691.

Borovec, T. D. \& Roemer, L. (1995). Perceived functions of worry among generalized anxiety disorder subjects: distraction from more emotional topics? Journal of Behavior Therapy and Experimental Psychiatry 26, 25-30.

Brugha, T., Bebbington, P., Tennant, C. \& Hurry, J. (1985). The List of Threatening Experiences: a subset of 12 life event categories with considerable long-term contextual threat. Psychological Medicine 15, 189-194.

Craske, M., Rapee, R., Jackel, L. \& Barlow, D. H. (1989). Qualitative dimensions of worry in DSM-III-R generalized anxiety disorder subjects and non-anxious controls. Behaviour Research and Therapy 27, 397-402.

Davey, G. (1994). Pathological worrying as exacerbated problemsolving. In Worrying: Perspectives on Theory, Assessment, and Treatment (ed. G. Davey and F. Tallis), pp. 35-60. Wiley: New York.

Diefenbach, G., McCarthy-Larzelere, M., Williamson, D., Mathews, A., Manguno-Mire, G. \& Bentz, B. (2001 b). Anxiety, depression and the content of worries. Depression and Anxiety 14, 247-250.

Diefenbach, G., Stanley, M. \& Beck, J. (2001a). Worry content reported by older adults with and without generalized anxiety disorder. Aging and Mental Health 5, 269-274.
Doucet, C., Ladouceur, R., Freeston, M. \& Dugas, M. (1998). Worry themes and a tendency to worry in older adults. Canadian Journal on Aging 17, 361-371.

Folkman, S., Lazarus, R. S., Pimley, S. \& Novacek, J. (1987). Age differences in stress and coping processes. Psychology and Aging $\mathbf{2}$, 171-184.

Hoyer, J., Becker, E. \& Roth, W. (2001). Characteristics of worry in GAD patients, social phobics and controls. Depression and Anxiety 13, 89-96.

Hunt, S., Wisocki, P. \& Yanko, J. (2003). Worry and use of coping strategies among younger and older adults. Anxiety Disorders 17, 547-560.

Jordanova, V., Wickramesinghe, C., Gerada, C. \& Prince, M. (2004). Validation of two survey diagnostic interviews among primary care attendees: a comparison of CIS-R and CIDI with SCAN ICD-10 diagnostic categories. Psychological Medicine 34, 1013-1024

Lewis, G., Pelosi, A., Araya, R. \& Dunn, G. (1992). Measuring psychiatric disorder in the community: a standardised assessment for use by lay interviewers. Psychological Medicine 22, 465-486.

Meltzer, H., Singleton, N., Lee, A., Bebbington, P., Brugha, T. \& Jenkins, R. (2002). The Social and Economic Circumstances of Adults with Mental Disorders. The Stationery Office: London.

Meyer, T., Miller, M., Metzger, R. \& Borkovec, T. (1990) Development and validation of the Penn State Worry Questionnaire. Behaviour Research and Therapy 28, 487-495.

Montorio, I., Nuevo, R., Márquez, M., Izal, M. \& Losada, A. (2003). Characterization of worry according to severity of anxiety in elderly living in the community. Aging and Mental Health 7, 334-341.

Powers, C., Wisocki, P. \& Whitbourne, S. (1992). Age differences and correlates of worrying in young and elderly adults. Gerontologist 32, $82-88$

Rodin, J. \& Timko, C. (1992). Sense of control, aging, and health. In Aging, Health and Behaviour (ed. M. G. Ory and R. P. Abeles), pp. 174-206. Sage: Thousand Oaks.

Roemer, L., Molina, S. \& Borkovec, T. (1997). An investigation of worry content among generally anxious individuals. Journal of Nervous and Mental Disease 185, 314-319.

Sanderson, W. \& Barlow, D. (1990). A description of patients diagnosed with DSM-III-R generalized anxiety disorder. Journal of Nervous and Mental Disease 178, 588-591.

Singleton, N., Bumpstead, R., O'Brien, M., Lee, A. \& Meltzer, H. (2001). Psychiatric Morbidity Among Adults Living in Private Households. The Stationery Office: London.

Skarborn, M. \& Nicki, R. (2000). Worry in pre- and post-retirement persons. International Journal of Aging and Human Development 50, 61-71.

Valliant, G. (1977). Adaptation to Life. Little, Brown \& Company: New York.

WHO (1993). The ICD-10 Classification of Mental and Behavioral Disorders. World Health Organization: Geneva. 